\title{
Indicadores para avaliação do Programa Nacional De Assistência Estudantil (PNAES)
}

\author{
Indicators for evaluation of the National Student Assistance Program \\ (PNAES)
}

\author{
Alex Trindade Barbosa ${ }^{\mathrm{I}}$, Eric Batista Ferreira ${ }^{\mathrm{II}}$, Marcelo Lacerda Rezende ${ }^{\mathrm{III}}$
}

\begin{abstract}
RESUMO
O presente trabalho objetivou o desenvolvimento de dois indicadores para avaliação e acompanhamento dos resultados do PNAES, tendo como base as taxas de retenção e evasão, um dos objetivos finais do Programa. Para testar a utilidade e as possibilidades dos indicadores, foi feita uma avaliação do Programa no âmbito da Universidade Federal de Alfenas (UNIFAL-MG). Os indicadores permitiram atestar a efetividade do PNAES na instituição estudada e apontou cursos que precisam de estudos específicos para compreender as razões de reprovações dos alunos, podendo ser utilizado em outras instituições e na avaliação de outros programas.
\end{abstract}

Palavras-Chave: Políticas públicas; Educação superior; Assistência estudantil; Números índices; Avaliação de Programas Públicos

\begin{abstract}
The present study aimed the development of two indicators for evaluation and monitoring of the results of the PNAES, based on the retention and evasion rates, one of the final objectives of the Program. In order to test the usefulness and possibilities of the indicators, an evaluation of the Program was made within the Federal University of Alfenas (UNIFAL-MG). The indicators allowed to attest the effectiveness of the PNAES in the institution studied and pointed out courses that need specific studies to understand the reasons for student retention, being able to be used in other institutions and in the evaluation of other programs.
\end{abstract}

Keywords: Public policies; Higher education; Student assistance; Index numbers; Evaluation of Public Programs

\footnotetext{
I Universidade Federal de Alfenas, Alfenas, MG - alex.trindade@unifal-mg.edu.br

IIUniversidade Federal de Alfenas, Alfenas, MG - eric.ferreira@unifal-mg.edu.br

III Universidade Federal de Alfenas, Alfenas, MG - marcelo.I.rezende@gmail.com
} 


\section{INTRODUÇÃo}

A institucionalização da assistência estudantil no Brasil ocorreu com a publicação da Portaria no 39 do Ministério da Educação (MEC), de 12 de dezembro de 2007 (BRASIL, 2007), que instituiu o Programa Nacional de Assistência Estudantil (PNAES). Destaca-se no preâmbulo desta Portaria, o fato de considerar a centralidade da assistência estudantil comoestratégia para combater as desigualdades sociais e regionais, bem como ampliar e democratizar as condições de acesso e permanência dos jovens no ensino superior público federal. Posteriormente, foi editado o Decreto no 7.234, de 19 de julho de 2010 (BRASIL, 2010), que dispõe sobre o PNAES, com a finalidade de ampliar as condições de permanência dos jovens na educação superior pública federal, conforme os objetivos:
Art. $2^{\circ}$ São objetivos do PNAES:
I - democratizar as condições de permanência dos jovens na educação superior pública federal;
II - minimizar os efeitos das desigualdades sociais e regionais na permanência e conclusão da educação superior;
III - reduzir as taxas de retenção e evasão; e
IV - contribuir para a promoção da inclusão social pela educação. (BRASIL, 2010)

Assim, como o objetivo do PNAES é minimizar os efeitos resultantes da vulnerabilidade socioeconômica na permanência do aluno assistido no ensino superior público, pode-se considerar que as ações de assistência estudantil devem ter o propósito de igualar as taxas de evasão e de reprovação dos alunos assistidos com as taxas dos alunos não assistidos, o que determinaria o sucesso do programa.

Dada sua importância, e atendendo aspectos legais, a avaliação do PNAES está prevista na Portaria no 39/2007, do MEC (BRASIL, 2007), e também no Decreto no 7.234/2010 (BRASIL, 2010), sendo atribuído às Instituições Federais de Ensino Superior (IFES) a fixação de mecanismos de acompanhamento e avaliação do PNAES com vistas ao cumprimento de seus objetivos.

Por trás da exigência legal de avaliação do PNAES, provavelmente está o entendimento de que a mesma pode ser considerada uma ferramenta gerencial, que auxilia os gestores no processo de tomada de decisão. É o que propõe Ala-Harja e Helgason (2000), segundo os quais a avaliação de um programa deve ser vista como um mecanismo para gerar informações que auxilie os gestores na execução dos recursos e nos processos de tomada de decisão. É importante salientar que a avaliação não resolve ou substituiu juízos subjetivos envolvidos na tomada de decisão, porém, permite o conhecimento dos resultados do programa analisado, o qual pode ser utilizado para melhorar a implementação do programa.

Portanto, é preciso avançar no sentido da maior institucionalização das avaliações não só no plano meramente administrativo, fiscalizatório ou burocrático-formal, mas no plano formativo, que busque incorporar o uso dos resultados obtidos para eventuais mudanças de rumo, reajustes e melhorias das políticas públicas, e o controle social das intervenções realizadas (BAUER e SOUZA, 2015). 
Nesse contexto, o presente trabalho objetivou o desenvolvimento de dois índices para avaliação e acompanhamento dos resultados do PNAES, tendo como base as taxas de retenção e evasão, um dos objetivos finais do Programa. Para testar a utilidade e as possibilidades dos indicadores, foi feita uma avaliação do Programa no âmbito da Universidade Federal de Alfenas (UNIFAL-MG).

Este artigo foi estruturado em cinco seções, incluindo esta introdução. A segunda seção apresenta a metodologia de elaboração do índice de evasão relativa e índice de reprovação relativa. Na terceira seção apresenta-se a UNIFAL-MG onde foi realizada a aplicação dos índices de evasão e reprovação relativos. Os resultados e discussão foram apresentados na seção 4 e as considerações finais encontram-se na quinta e última seção.

\section{METODOLOGIA}

A metodologia está dividida em três subseções. A primeira apresenta o índice de evasão relativa e a taxa de evasão. A segunda subseção mostra o índice de reprovação relativa e a taxa de reprovação. Por fim, uma terceira subseção faz considerações sobre a aplicação dos índices.

\section{1 Índice de evasão relativa}

Para comparar a proporção de alunos assistidos pelo PNAES com a proporção de alunos não assistidos pelo PNAES, foi elaborado o índice de evasão relativa (Iev), conforme equação (1.1). A interpretação do indicador é apresentada no Quadro 1.

$$
I e v=\frac{\frac{Q E v n a}{T n a}-\frac{Q E v a}{T a}}{\frac{Q E v n a}{T n a}+\frac{Q E v a}{T a}}
$$

em que Iev é o índice de evasão relativa; QEvna: quantidade de alunos evadidos não assistidos; Tna: total de alunos não assistidos; QEva: quantidade de alunos evadidos e assistidos; Ta: total de alunos assistidos; QEvna, QEva, Tna e Ta são números naturais; $1,00 \leq$ Iev $\leq 1,00$; sendo:

$$
T n a \neq 0 ; T a \neq 0 ;\left(\frac{Q E v n a}{T n a}\right)+\left(\frac{Q E v a}{T a}\right) \neq 0
$$

\begin{tabular}{|c|c|c|c|c|}
\hline$-1,00$ & ---------------------- & 0,00 & |------------------- & \multirow{3}{*}{$\begin{array}{c}1,00 \\
\text { QEva }=0 \text { e } \\
\text { QEvna > } 0\end{array}$} \\
\hline QEvna $=0 \mathrm{e}$ & QEva > QEvna & QEva $=$ QEvna & QEva $<$ QEvna & \\
\hline QEva $>0$ & Tna & Tna & Tna & \\
\hline $\begin{array}{l}\text { nenhum aluno } \\
\text { não assistido } \\
\text { evadiu e pelo } \\
\text { menos um aluno } \\
\text { assistido evadiu }\end{array}$ & $\begin{array}{l}\text { maior proporção } \\
\text { de evasão de } \\
\text { alunos assistidos }\end{array}$ & $\begin{array}{l}\text { igual proporção } \\
\text { de evasão de } \\
\text { alunos não } \\
\text { assistidos e } \\
\text { assistidos }\end{array}$ & $\begin{array}{c}\text { menor } \\
\text { proporção de } \\
\text { evasão de } \\
\text { alunos assistidos }\end{array}$ & $\begin{array}{l}\text { nenhum aluno } \\
\text { assistido evadiu } \\
\text { e pelo menos } \\
\text { um aluno não } \\
\text { assistido evadiu }\end{array}$ \\
\hline
\end{tabular}

QUADRO 1 - Interpretação do índice de evasão relativa (Iev)

Elaboração dos autores. 
O índice de evasão relativa (Iev) compara proporcionalmente a evasão de alunos assistidos e não assistidos de uma população de alunos em um período determinado. Quando o resultado do indicador é 0,00 (zero), os alunos assistidos estão no mesmo patamar dos alunos não assistidos no aspecto da evasão, independentemente da taxa de evasão do curso ser alta ou baixa. Nesta situação, o PNAES atingiu o objetivo discriminado no inciso III, do art. 20, do Decreto no 7.234/2010: "minimizar os efeitos das desigualdades sociais e regionais na permanência e conclusão do ensino superior".

Se o índice de evasão relativa é maior do que zero, a proporção de alunos assistidos evadidos é menor. Entretanto, não significa necessariamente que os alunos assistidos tiveram baixa taxa de evasão. Dessa maneira, em um curso em que os alunos assistidos e não assistidos tiveram ambos $80 \%$ de evasão, o indicador de evasão é zero $($ Iev $=0,00)$. Dessa forma, foi calculada uma taxa de evasão para cada curso, com o objetivo de ampliar o entendimento da situação de cada um deles. Para a análise da taxa de evasão é utilizada a equação (1.2):

$$
T e v=\left(\frac{Q E v n a+Q E v a}{T n a+T a}\right) 100
$$

em que Tev é a taxa de evasão (\%); QEvna: quantidade de alunos evadidos não assistidos; QEva: quantidade de alunos evadidos e assistidos; Tna. total de alunos não assistidos; Ta: total de alunos assistidos; QEvna, QEva, Tna e Ta são números naturais; sendo $T$ na $+T a \neq 0$.

\section{2 Índice de reprovação relativa}

É objetivo do PNAES reduzir as taxas de retenção, assim, para analisar a retenção, será considerada a reprovação em disciplinas, que, de acordo com Ciribelli (2015), poderá implicar na ultrapassagem do tempo previsto para integralização curricular e, por conseguinte, desencadear retenção no curso superior. $O$ índice de reprovação relativa compara a proporção de alunos não assistidos, com pelo menos uma reprovação, com a proporção de alunos assistidos com pelo menos uma reprovação. $O$ índice de reprovação relativa foi definido na equação (2.1) e a interpretação do indicador consta no Quadro 2.

$$
I R p=\frac{\frac{Q R p n a}{T n a}-\frac{Q R p a}{T a}}{\frac{Q R p n a}{T n a}+\frac{Q R p a}{T a}}
$$

em que IRp é o índice de reprovação relativa; $Q R p n a$ : quantidade de alunos não assistidos com pelo menos uma reprovação; Tna: total de alunos não assistidos; QRpa: quantidade de alunos assistidos com pelo menos uma reprovação; Ta: total de alunos assistidos; QRpna, QRpa, Tna e Ta são números naturais; $-1,00 \leq I R p \leq 1,00$; sendo:

$$
T n a \neq 0 ; T a \neq 0 ;\left(\frac{Q R p n a}{T n a}\right)+\left(\frac{Q R p a}{T a}\right) \neq 0
$$


QUADRO 2 - Interpretação do índice de reprovação relativa (IRp)

\begin{tabular}{|c|c|c|c|c|}
\hline$-1,00$ & ----------------------- & 0,00 & ----------------------- & 1,00 \\
\hline $\begin{array}{c}Q R p_{n a}=0 \mathrm{e} \\
Q R p_{a}>0\end{array}$ & $\frac{Q R p_{a}}{T_{a}}>\frac{Q R p_{n a}}{T_{n a}}$ & $\frac{Q R p_{a}}{T_{a}}=\frac{Q R p_{n a}}{T_{n a}}$ & $\frac{Q R p_{a}}{T_{a}}<\frac{Q R p_{n a}}{T_{n a}}$ & $\begin{array}{l}Q R p_{a}=0 \mathrm{e} \\
Q R p_{n a}>0\end{array}$ \\
\hline $\begin{array}{l}\text { nenhum aluno } \\
\text { não assistido } \\
\text { teve reprovação } \\
\text { e pelo menos um } \\
\text { aluno assistido } \\
\text { reprovou em } \\
\text { alguma disciplina }\end{array}$ & $\begin{array}{c}\text { maior proporção } \\
\text { de reprovação } \\
\text { de alunos } \\
\text { assistidos }\end{array}$ & $\begin{array}{c}\text { igual } \\
\text { proporção de } \\
\text { reprovação de } \\
\text { alunos } \\
\text { assistidos e } \\
\text { não assistidos }\end{array}$ & $\begin{array}{c}\text { menor } \\
\text { proporção de } \\
\text { reprovação de } \\
\text { alunos } \\
\text { assistidos }\end{array}$ & $\begin{array}{l}\text { nenhum aluno } \\
\text { assistido teve } \\
\text { reprovação e } \\
\text { pelo menos um } \\
\text { aluno não } \\
\text { assistido } \\
\text { reprovou em } \\
\text { alguma disciplina }\end{array}$ \\
\hline
\end{tabular}

Elaboração dos autores.

O índice de reprovação relativa tem como objetivo comparar as taxas de reprovação entre os alunos assistidos e não assistidos, independe da magnitude dessas taxas. Dessa maneira, um indicador de reprovação igual a zero não significa necessariamente que não teve reprovação dos alunos assistidos, mas representa que as taxas dos dois grupos avaliados são iguais. Quando o índice de reprovação relativa for igual a zero $(0,00)$, significa que as ações de assistência estudantil diminuíram os efeitos resultantes das desigualdades sociais na permanência dos alunos assistidos, colocando os alunos assistidos e não assistidos em um mesmo patamar com relação ao rendimento acadêmico. Para analisar a taxa de reprovação foi definida a equação (2.2).

$$
T R p=\left(\frac{Q R p n a+Q R p a}{T n a+T a}\right) 100
$$

em que TRp é a taxa de reprovação (\%); QRpna. quantidade de alunos não assistidos com pelo menos uma reprovação; QRpa: quantidade de alunos assistidos com pelo menos uma reprovação; Tna: total de alunos não assistidos; Ta: total de alunos assistidos; QRpna, QRpa, Tha e Ta são números naturais; sendo $T n a+T a \neq 0$.

\subsection{Considerações para a interpretação dos índices}

O Ministério do Planejamento, Orçamento e Gestão, por meio da Secretaria do Orçamento Federal, divulga anualmente o cadastro das ações orçamentárias constantes na Lei Orçamentária Anual ${ }^{1}$. Nesse cadastro a ação 4002 (Assistência ao Estudante de Ensino Superior), do programa 2032 (Educação Superior) tem como produto "aluno assistido" até o ano de 2013, a partir de 2014 o produto é "benefício concedido".

Entretanto, sendo um dos objetivos do PNAES minimizar os efeitos das desigualdades sociais na permanência e na conclusão da educação superior (BRASIL, 2010), pode-se considerar como padrão de referência a igualdade da proporção de evasão e de reprovação dos alunos assistidos pelo PNAES com a proporção dos alunos não assistidos pelo programa. Então, os auxílios (alimentação, permanência, creche e pedagógico) possuem o propósito de diminuir os efeitos resultantes da vulnerabilidade socioeconômica dos alunos assistidos, colocando-os no mesmo patamar dos alunos não

1. Disponível em: http://www.orcamentofederal.gov.br/clientes/portalsof/portalsof/orcamentosanuais. Acesso em: 27 maio 2018 
assistidos no que se refere à permanência e ao rendimento acadêmico. Assim, apesar do produto final do PNAES ser, desde 2014, o "benefício concedido", no presente trabalho se propõe que a avaliação seja feita a partir dos indicadores de evasão e reprovação dos alunos assistidos.

A avaliação do PNAES foi realizada com o propósito de responder à pergunta se o PNAES foi um sucesso ou fracasso. Para isso, foi definida a efetividade como critério de avaliação para aferir os resultados, calculados os índices para quantificar os resultados e adotado como padrão de referência para comparação o aluno não assistido.

O PNAES terá sucesso se os índices (Iev e IRp) forem iguais ou maiores do que zero. Este resultado dos índices significa que os alunos assistidos, proporcionalmente, evadem e reprovam igual ou menos que os alunos não assistidos.

Os índices comparam por meio de um teste, a diferença de proporção entre os alunos assistidos e não assistidos pelo PNAES, de forma que é necessário na aplicação dos índices (evasão e reprovação), que o curso analisado tenha pelo menos um aluno assistido e um aluno não assistido. Portanto, não se aplicam os índices na hipótese em que o total de alunos assistidos ( Ta) ou total de alunos não assistidos (Tna) for igual a zero.

No cálculo dos índices, são consideradas as reprovações e as evasões dos alunos no período de ingresso até o segundo semestre de 2016. Então, para os ingressantes no 10/2014 são contabilizadas as reprovações e evasões dos alunos em seis semestres, enquanto para os ingressantes no 2\%/2014, cinco semestres. O cálculo dos índices considera somente os alunos que ingressaram pelo processo seletivo do Sistema de Seleção Unificada (Sisu).

Para o cálculo do índice de reprovação relativa e da taxa de reprovação, foram excluídos os alunos desistentes no semestre de ingresso. Essa observação deve-se ao fato que o aluno, ao cancelar a matrícula no $1^{0}$ semestre, não cursou nenhuma disciplina, consequentemente, não teve nenhuma reprovação. Assim, o aluno desistente no ingresso foi considerado evadido e contribuiu para taxa de evasão e índice de evasão relativa, mas não foi contabilizado para o índice e taxa de reprovação.

As interpretações decorrentes dos valores dos índices são aplicadas somente para população sobre a qual o índice foi calculado. Por exemplo, o Iev calculado para os ingressantes em 1\%/2014 no curso de Biotecnologia, não se aplica à população total de alunos cursando Biotecnologia, no segundo semestre de 2016, mas somente para aqueles discentes que fizeram matrícula em Biotecnologia no primeiro semestre de 2014.

\section{APLICAÇÃO DOS ÍNDICES NA UNIFAL-MG}

Na UNIFAL-MG há ações de assistência estudantil anteriores à publicação da Portaria no 39/2007 do MEC. No ano de 2004, foi criada a Secretaria de Assuntos Comunitários e Cultura (SACC), vinculada à Pró-Diretoria de Extensão da então EFOA/CEUFE. A Escola de Farmácia e Odontologia de Alfenas (EFOA), fundada em 1914, transformou-se em Centro Universitário Federal em 2001 (EFOA/CEUFE) e em Universidade Federal de Alfenas em 2005, pela Lei Federal no 11.154, de 29 de julho de 2005 (SOARES, 2016). 
A SACC, em 2004, oferecia aos alunos de baixa renda a isenção da taxa de inscrição no processo seletivo para ingresso, desde que comprovada situação de carência. Já no ano de 2005, com recursos arrecadados de taxas de inscrição, foi implantado o Programa Bolsa Trabalho que consistia no exercício de alguma atividade remunerada pelo aluno carente sob a supervisão de um docente ou técnico administrativo em educação, não podendo acumular com outro tipo de bolsa acadêmica da universidade.

No ano de 2007, criou-se a Comissão Provisória de Assistência Estudantil (COPAES) substituindo a SACC na gestão da assistência estudantil. O Programa Bolsa Trabalho foi renomeado para Bolsa Atividade. Em 2010 foi criada a Pró-Reitoria de Assuntos Comunitários e Estudantis (PRACE), órgão responsável atualmente pelo planejamento, execução e avaliação do Programa Nacional de Assistência Estudantil - PRACE - (SOARES, 2016).

O Programa de Assistência Estudantil foi regulamentado em 2014, com a edição da Resolução no 19/2014, de 06 de fevereiro de 2014, do Conselho Universitário da UNIFALMG (UNIFAL-MG, 2014). Esta resolução fixa as diretrizes sobre o funcionamento do Programa Nacional de Assistência Estudantil oferecido pela Universidade Federal de Alfenas, por meio da Pró-Reitoria de Assuntos Comunitários e Estudantis (PRACE), fundamentada em uma política de assistência estudantil que contemple alunos de graduação na modalidade presencial, cuja vulnerabilidade socioeconômica pode dificultar a permanência na UNIFAL-MG

O Programa de Assistência Estudantil na UNIFAL-MG compreende os seguintes auxílios:

Art. 30 Os Programas de Assistência Estudantil representados nesta Resolução compreendem auxílios para alimentação, para permanência, para creche e de apoio pedagógico ao estudante de graduação, modalidade presencial, conforme sua classificação de vulnerabilidade socioeconômica.

Parágrafo único - O auxílio-permanência é instituído para atender prioritariamente as necessidades básicas de moradia e transporte, previstas pelo PNAES e segundo critérios da UNIFAL-MG.

Art. $14^{\circ} \mathrm{O}$ auxílio a atividades pedagógicas possui natureza social e pedagógica e tem por finalidade conceder ao estudante com assistência estudantil apoio pecuniário nas seguintes situações:

I - atividade de campo;

II - participação em eventos científicos e culturais;

III - isenção de taxas em eventos científicos e culturais da UNIFAL-MG;

IV - instrumental de aulas práticas;

$V$ - curso de idioma;

VI - participação em eventos esportivos representando a UNIFAL-MG;

VII - participação em eventos de representação do movimento estudantil oficiais do DCE (Diretório Central dos Estudantes), DAs (Diretórios Acadêmicos) e CAs (Centros Acadêmicos) (UNIFAL-MG, 2014).

No presente trabalho, a população analisada foi de 5.128 alunos, englobando todos os cursos de graduação presencial do campus Sede e da Unidade Educacional Santa Clara em Alfenas/MG, e os cursos dos campiavançados da UNIFAL-MG: campus Avançado de Poços de Caldas/MG e campus Avançado de Varginha/MG. Dessa forma, foi realizado o 
censo da população total dos ingressantes no primeiro e segundo semestres de 2014 , o que torna desnecessária a inferência estatística. $O$ quantitativo de alunos ingressantes por semestre está discriminado na Tabela 1.

TABELA 1 - Quantitativo de alunos ingressantes por semestre

\begin{tabular}{cccc}
\hline Semestre & $\begin{array}{c}\text { Quantidade de } \\
\text { alunos assistidos pelo } \\
\text { PNAES }\end{array}$ & $\begin{array}{c}\text { Quantidade de } \\
\text { alunos não assistidos } \\
\text { pelo PNAES }\end{array}$ & $\begin{array}{c}\text { Total de alunos } \\
\text { ingressantes }\end{array}$ \\
\hline $1 \% / 2014$ & 291 & 885 & 1.176 \\
\hline $2 \% / 2014$ & 66 & 394 & 460 \\
\hline $1 \% / 2015$ & 261 & 959 & 1.220 \\
\hline $2 \% / 2015$ & 93 & 417 & 510 \\
\hline $1 \% / 2016$ & 251 & 1032 & 1.283 \\
\hline $2 \% / 2016$ & 63 & 416 & 479 \\
\hline
\end{tabular}

Fonte: Dados da pesquisa

Elaboração dos autores.

Para o recorte temporal da presente pesquisa (2014 a 2016), foi definido o início da implementação da Resolução no 19/2014, de 06 de fevereiro de 2014, do Conselho Universitário da UNIFAL-MG, que regulamenta os Programas de Assistência Estudantil na UNIFAL-MG.

Para cada aluno foram obtidos os seguintes dados nesta pesquisa: Cadastro de Pessoa Física (CPF), número de matrícula, modalidade (bacharelado/licenciatura), ocorrência de evasão (desistente/desligado/processo de desligamento), data da evasão, reprovações dos ingressantes no 1\%/2014 e no 20/2014 desde do ingresso até o 2\%/2016

Foram ainda considerados os benefícios concedidos para cada um dos alunos: auxílios permanência, alimentação, creche e a atividades pedagógicas (campo, participação em eventos científicos e culturais, isenção de taxas em eventos científicos e culturais da UNIFAL-MG, instrumental de aulas práticas, curso de idioma, participação em eventos esportivos representando a UNIFAL-MG e participação em eventos de representação do movimento estudantil oficiais do Diretório Central dos Estudantes, Diretórios Acadêmicos e Centros Acadêmicos).

A variável ocorrência de evasão possui três categorias: desistente, desligado e processo de desligamento. Desistente é quando o aluno solicita o cancelamento total da matrícula, podendo ser realizado a qualquer momento ${ }^{2}$. As situações que o aluno foi considerado desligado estão discriminadas no Regulamento Geral dos Cursos de Graduação (UNIFAL-MG, 2016):

Art. 209. O desligamento de discentes dos cursos de graduação ocorrerá quando:

I - o discente receber sanção disciplinar que caracterize a expulsão;

2. Procedimento para cancelamento de matrícula na UNIFAL-MG disponível em: http://www.unifalmg.edu.br/drgca/cancelamento. Acesso em: 27 maio 2018 
II - não integralizar o curso no tempo máximo estabelecido no Projeto Pedagógico; III - não renovar a matrícula nos prazos estabelecidos no Calendário Acadêmico.

$\S 1^{\circ} \mathrm{O}$ desligamento será feito por portaria do Reitor.

O desligamento do discente tem um rito previsto na Resolução no 25/2015, de 23 de novembro de 2015, que estabelece os atos e os trâmites do processo de desligamento de discentes de graduação no âmbito da UNIFAL-MG. Dessa maneira, o aluno será classificado na categoria "processo de desligamento", durante o período do trâmite do processo até o desligamento realizado com a publicação de Portaria do Reitor.

O aluno que não renovar o vínculo nos prazos estabelecidos no calendário acadêmico, também é considerado desistente até o dia que se inicia o processo de desligamento, a partir deste dia o aluno é categorizado como "processo de desligamento" e, quando editada a portaria de desligamento do Reitor, o aluno é classificado como "desligado".

O projeto de pesquisa foi submetido ao Comitê de Ética em Pesquisa da Universidade Federal de Alfenas e aprovado pelo parecer $n^{\circ}$ 1.980.281. O estudo seguiu às diretrizes éticas em pesquisa, garantindo a confidencialidade dos dados da pesquisa.

\section{RESULTADOS E DISCUSSÃO}

Os resultados da aplicação dos índices na UNIFAL-MG estão divididos em duas subseções. A primeira apresenta os resultados encontrados na aplicação do índice de evasão relativa e a segunda subseção mostra os resultados pertinentes ao índice de reprova4ção relativa.

\subsection{0 índice de evasão relativa (lev)}

O índice de evasão relativa permite uma comparação proporcional entre a evasão de alunos assistidos e não assistidos de uma população total, em determinado período. Entretanto, não quantifica essa evasão. Para isso, foi calculada a taxa de evasão para os cursos da Unifal-MG (Tabela 2) e que, interpretada junto com o Iev, permite um entendimento melhor do papel da assistência estudantil. Assim, considerando os alunos ingressantes no $1 \% / 2014$, os cursos que tiveram maior evasão foram os de Matemática Licenciatura (68\%), Química Licenciatura (62\%) e Geografia Bacharelado (56\%).

As taxas de evasão estão relacionadas ao curso, independente do aluno ser atendido ou não pelo PNAES. Como pode ser observado na Tabela 2, o curso de Matemática Licenciatura apresentou Tev $=68 \%$ e Iev $=1,00$. Esse valor do índice de evasão relativa significa que nenhum aluno assistido evadiu e pelo menos um aluno não assistido evadiu. Entretanto, a Tev de $68 \%$ mostra um elevado índice de evasão para o curso. Portanto, concluiu-se que o PNAES não só atingiu o objetivo de minimizar os efeitos das desigualdades sociais com relação à evasão do curso de Matemática Licenciatura, como pode ter sido importante para garantir a permanência dos assistidos no curso. Destaca-se que dos sete alunos assistidos nenhum evadiu, enquanto dos 33 alunos não assistidos, 27 evadiram. 
Na Tabela 2 observa-se que dos 27 cursos, o índice de evasão relativa foi calculado para 25 cursos. Os cursos com taxas de evasão iguais a zero, também tiveram Iev $=0$. Os índices de evasão relativas iguais a zero significam que os alunos assistidos dos cursos de Ciências Econômicas, Engenharia de Minas e Engenharia Química estão no mesmo patamar dos alunos não assistidos no aspecto pertinente à evasão, isso é, a proporção de evasão dos alunos assistidos é igual a proporção de evasão dos alunos não assistidos.

Ainda examinando a Tabela 2, 12 cursos possuem o Iev entre 0,00 e 1,00 e 10 cursos apresentam Iev $=1,00$. Nos cursos de Ciências Econômicas, Engenharia de Minas e Engenharia Química com índices de evasão relativas iguais a zero, o PNAES já teve impacto positivo de igualar os alunos assistidos e não assistidos com relação à proporção de evasão. Ademais, em 12 cursos os alunos assistidos evadiram em menor proporção (0 $<$ Iev < 1). Em 10 cursos os alunos assistidos não tiveram evasão, enquanto pelo menos um aluno não assistido evadiu ( Iev $=1$ ). Esse resultado reforça a efetividade do PNAES em relação à evasão para os alunos ingressantes no 10/2014.

TABELA 2 - Índice de evasão relativa e taxa de evasão relativa dos alunos ingressantes no $10 / 2014$

\begin{tabular}{llcc}
\hline \multicolumn{1}{c}{ Curso } & Modalidade & $\begin{array}{c}\text { Iev- Índice de } \\
\text { evasão relativa }\end{array}$ & Tev- Taxa de evasão \\
\hline Ciências Econômicas & Bacharelado & 0,00 & $0 \%$ \\
\hline Engenharia de Minas & Bacharelado & 0,00 & $0 \%$ \\
\hline Engenharia Química & Bacharelado & 0,00 & $0 \%$ \\
\hline Ciências Sociais & Licenciatura & 0,05 & $55 \%$ \\
\hline Nutrição & Bacharelado & 0,22 & $30 \%$ \\
\hline Geografia & Bacharelado & 0,39 & $56 \%$ \\
\hline Química & Licenciatura & 0,41 & $62 \%$ \\
\hline Geografia & Licenciatura & 0,49 & $44 \%$ \\
\hline Farmácia & Bacharelado & 0,51 & $31 \%$ \\
\hline Ciência da Computação & Bacharelado & 0,65 & $35 \%$ \\
\hline Pedagogia & Licenciatura & 0,66 & $25 \%$ \\
\hline Ciências Biológicas & Bacharelado & 0,67 & $33 \%$ \\
\hline BICE & Bacharelado & 0,74 & $32 \%$ \\
\hline Física & Licenciatura & 0,75 & $54 \%$ \\
\hline BICT & Bacharelado & 0,80 & $33 \%$ \\
\hline Biomedicina & Bacharelado & 1,00 & $25 \%$ \\
\hline Biotecnologia & Bacharelado & 1,00 & $20 \%$ \\
\hline Ciências Sociais & Bacharelado & 1,00 & $52 \%$ \\
\hline Enfermagem & Bacharelado & 1,00 & $18 \%$ \\
\hline Fisioterapia & Bacharelado & 1,00 & $21 \%$ \\
\hline História & Licenciatura & 1,00 & $39 \%$ \\
\hline Letras & Licenciatura & 1,00 & $36 \%$ \\
\hline Matemática & Licenciatura & 1,00 & $0 \% \%$ \\
\hline Medicina & Bacharelado & 1,00 & \\
\hline Odontologia & Bacharelado & 1,00 & $39 \%$ \\
\hline Ciências Atuariais & Bacharelado & nenhum assistido & \\
\hline & & & \\
\hline
\end{tabular}




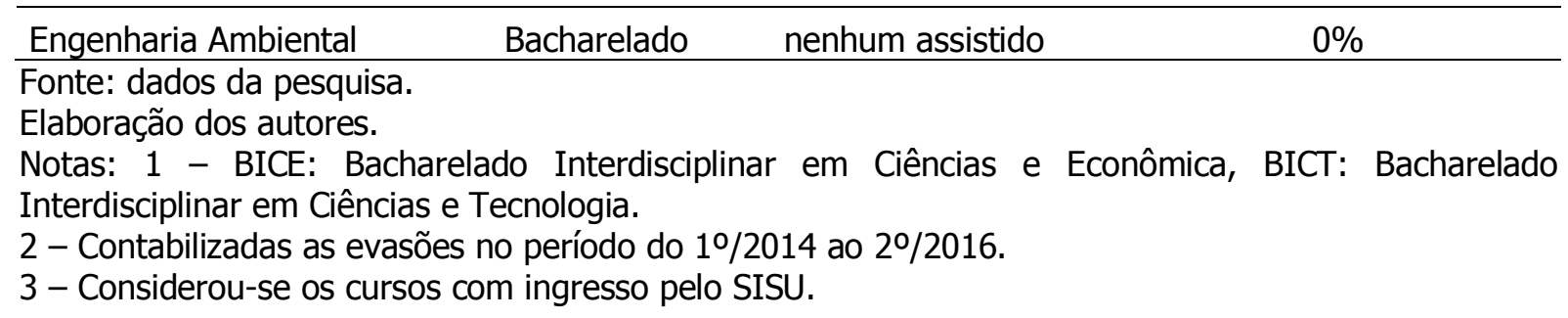

Segundo estudos de Gerba (2014), no Instituto Federal de Santa Catarina e de Silva et al. (2012), na Universidade Federal do Piauí, um dos motivos para evasão dos cursos de licenciaturas é o descontentamento com as perspectivas do profissional da educação com relação ao salário, como também a desvalorização social do professor, fatores que extrapolam as dificuldades dos alunos em se manterem nos cursos. Portanto, é necessário também atuar além da assistência estudantil para combater essa evasão. Nesses casos, Gerba (2014) sugere a intervenção da universidade junto à sociedade pela valorização do professor, ações para inserir o aluno de licenciatura no mercado de trabalho e o fortalecimento da assistência estudantil.

No segundo semestre, na UNIFAL-MG, a quantidade de cursos oferecidos é menor, como pode ser observado na Tabela 3. Ocorreu ingresso pelo SiSU de apenas sete cursos no segundo semestre de 2014. Dos sete cursos do 20/2014, foi calculado o índice de evasão relativa para seis cursos. Não se aplicou o índice de evasão relativa para o curso de Engenharia de Minas, uma vez que não houve aluno assistido.

Entre os cursos do 2\%/2014 (Tabela 3), os cursos que tiveram maior evasão foram Ciências Biológicas Licenciatura (52\%), Química Bacharelado (39\%) e Bacharelado Interdisciplinar em Ciências e Economia (37\%).

Excluindo o curso de Engenharia de Minas, observa-se na Tabela 3 que, os cursos tiveram o índice de evasão relativa maior do que zero, isso significa que a proporção de alunos assistidos evadidos foi menor que a proporção de alunos não assistidos. Além disso, nos cursos de Bacharelado Interdisciplinar em Ciência e Tecnologia, Farmácia e Odontologia os alunos assistidos não evadiram ( Iev $=1,00$ ), enquanto ocorreu evasão de alunos não assistidos. Portanto, o PNAES foi efetivo no aspecto pertinente à evasão para os alunos ingressantes no segundo semestre de 2014.

TABELA 3 - Índice de evasão relativa e taxa de evasão dos alunos ingressantes no $2 \% / 2014$

\begin{tabular}{llcc}
\hline \multicolumn{1}{c}{ Curso } & Modalidade & $\begin{array}{c}\text { Iev- Índice de evasão } \\
\text { relativa }\end{array}$ & Tev- Taxa de evasão \\
\hline Química & Bacharelado & 0,52 & $39 \%$ \\
\hline Ciências Biológicas & Licenciatura & 0,61 & $52 \%$ \\
\hline BICE & Bacharelado & 0,72 & $37 \%$ \\
\hline BICT & Bacharelado & 1,00 & $26 \%$ \\
\hline Farmácia & Bacharelado & 1,00 & $25 \%$ \\
\hline Odontologia & Bacharelado & 1,00 & $6 \%$ \\
\hline Engenharia de Minas & Bacharelado & nenhum assistido & $0 \%$ \\
\hline
\end{tabular}

Fonte: dados da pesquisa.

Elaboração dos autores 
Notas: 1 - BICE: Bacharelado Interdisciplinar em Ciências e Econômica, BICT: Bacharelado Interdisciplinar em Ciências e Tecnologia.

2 - Contabilizadas as evasões no período de 20/2014 ao 2\%/2016.

3 - Considerou-se os cursos com ingresso pelo SISU.

Explorando a Tabela 3, constata-se que o curso BICE com Tev $=37 \%$ foi um dos cursos com maior taxa de evasão entre os alunos ingressantes, no segundo semestre de 2014 na UNIFAL-MG. Andrade (2014) verificou que nos cursos de Bacharelados Interdisciplinares na UFBA as causas predominantes de evasão foram a escolha por outro curso tradicional, a lentidão da UFBA no estabelecimento de normas sobre o BI, os motivos financeiros e o baixo rendimento desempenho acadêmico.

Sendo a questão financeira um dos motivos de evasão do Bacharelado Interdisciplinar na UFBA, pode-se levantar a hipótese de que, na UNIFAL-MG, para o curso BICE $($ Iev $=0,72)$ o auxílio financeiro da assistência estudantil teve impacto positivo na permanência dos alunos assistidos, pois esses evadiram em menor proporção. Assim, reforça-se a importância da questão financeira na redução da evasão dos alunos com vulnerabilidade econômica.

\subsection{0 índice de reprovação relativa $(I R p)$}

Para análise do IRp foi calculada também a Taxa de Reprovação (TRp), com o objetivo de auxiliar no entendimento do índice. Os cursos com maiores taxas de reprovação (Figura 14) foram Química Licenciatura (100\%), Bacharelado Interdisciplinar em Ciências e Economia (98\%) e Física Licenciatura (97\%).

O curso de Química Licenciatura foi o segundo com maior taxa de evasão (Tabela 2) e o curso com maior taxa de reprovação (Tabela 4), entre os cursos do primeiro semestre de 2014, reforçando a hipótese de que as reprovações contribuem para os casos de evasão, como observado por Ciribelli (2015), na Universidade Federal de Juiz de Fora.

Analisando a Tabela 4, nove cursos tiveram índices de reprovações relativas menores do que zero, isso significa que a proporção de alunos assistidos com pelo menos uma reprovação foi maior do que a proporção de alunos não assistidos com reprovação nos cursos de Nutrição, Geografia Bacharelado, Biotecnologia, Ciências Sociais Licenciatura, Biomedicina, Ciências Biológicas Bacharelado, BICT, BICE e Letras Licenciatura.

Considerando a escala de $-1,00$ até 0,00 , quando o valor negativo do índice de reprovação relativa estiver próximo de zero, mais se aproxima da igualdade de proporção entre alunos assistidos e não assistidos. Exemplificando, no curso de Letras Licenciatura $(I R p=-0,01), 12$ dos 13 assistidos reprovaram (proporção de 92,30\%) e 28 dos 31 não assistidos reprovaram (proporção de 90,32\%). Em contrapartida, quanto mais o índice de reprovação relativa aproxima de $-1,00$, maior a proporção de alunos assistidos que reprovaram. No curso de Nutrição, 13 dos 14 alunos assistidos reprovaram (proporção de 92,85\%) e 23 dos 33 alunos não assistidos reprovaram (proporção de 69,69\%).

Ainda observando os dados da Tabela 4, há quatro cursos com IRp $=0$, o que significa uma proporção igual de alunos assistidos e não assistidos com relação à reprovação: Ciências Econômicas, Engenharia de Minas, Engenharia Química e Química Licenciatura. 
O curso de Química teve $100 \%$ de reprovação e os cursos de Ciências Econômicas, Engenharia de Minas e Engenharia Química tiveram taxas de reprovações nulas. Nesses cursos com $I R p=0$, o PNAES já atingiu objetivo de colocar os alunos não assistidos e assistidos no mesmo patamar com relação à reprovação.

Quanto ao curso de Química Licenciatura, a reprovação é decorrente de dificuldades enfrentadas tanto pelos alunos assistidos quanto pelos não assistidos, assim é conveniente uma intervenção da universidade para avaliar as dificuldades desses alunos.

A efetividade do PNAES $(\operatorname{IRp}=0,06)$ com relação à reprovação para o curso de Física Licenciatura (Tabela 4) não diminui a necessidade de um estudo para levantar as dificuldades tanto dos alunos assistidos quanto dos não assistidos, uma vez que a taxa de reprovação de $97 \%$ é alta. A interpretação concomitante do $I R p=0,06$ com a $T R p=$ $97 \%$ indica que os alunos assistidos, mesmo diante das dificuldades do curso de Física Licenciatura, reprovam proporcionalmente menos que os alunos não assistidos.

TABELA 4 - Índice de reprovação relativa e taxa de reprovação dos alunos ingressantes no $1 \% / 2014$

\begin{tabular}{llcc}
\hline \multicolumn{1}{c}{ Curso } & Modalidade & $\begin{array}{c}\text { IRp- Índice de } \\
\text { reprovação relativa }\end{array}$ & $\begin{array}{c}\text { TRp-Taxa de } \\
\text { reprovação }\end{array}$ \\
\hline Nutrição & Bacharelado & $-0,14$ & $77 \%$ \\
\hline Geografia & Bacharelado & $-0,10$ & $88 \%$ \\
\hline Biotecnologia & Bacharelado & $-0,10$ & $84 \%$ \\
\hline Ciências Sociais & Licenciatura & $-0,08$ & $86 \%$ \\
\hline Biomedicina & Bacharelado & $-0,08$ & $67 \%$ \\
\hline Ciências Biológicas & Bacharelado & $-0,06$ & $93 \%$ \\
\hline BICT & Bacharelado & $-0,03$ & $79 \%$ \\
\hline BICE & Bacharelado & $-0,02$ & $98 \%$ \\
\hline Letras & Licenciatura & $-0,01$ & $91 \%$ \\
\hline Ciências Econômicas & Bacharelado & 0,00 & $0 \%$ \\
\hline Engenharia de Minas & Bacharelado & 0,00 & $0 \%$ \\
\hline Engenharia Química & Bacharelado & 0,00 & $0 \%$ \\
\hline Química & Licenciatura & 0,00 & $100 \%$ \\
\hline Odontologia & Bacharelado & 0,03 & $49 \%$ \\
\hline Geografia & Licenciatura & 0,05 & $88 \%$ \\
\hline Física & Licenciatura & 0,06 & $97 \%$ \\
\hline Farmácia & Bacharelado & 0,07 & $83 \%$ \\
\hline Ciência da Computação & Bacharelado & 0,09 & $93 \%$ \\
\hline Fisioterapia & Bacharelado & 0,13 & $56 \%$ \\
\hline Enfermagem & Bacharelado & 0,21 & $75 \%$ \\
\hline História & Licenciatura & 0,25 & $68 \%$ \\
\hline Matemática & Licenciatura & 0,36 & $83 \%$ \\
\hline Pedagogia & Licenciatura & 0,39 & $65 \%$ \\
\hline Medicina & Bacharelado & 0,52 & $28 \%$ \\
\hline Ciências Sociais & Bacharelado & 1,00 & $81 \%$ \\
\hline Ciências Atuariais & Bacharelado & nenhum assistido & \\
\hline & & & $0 \%$ \\
\hline
\end{tabular}




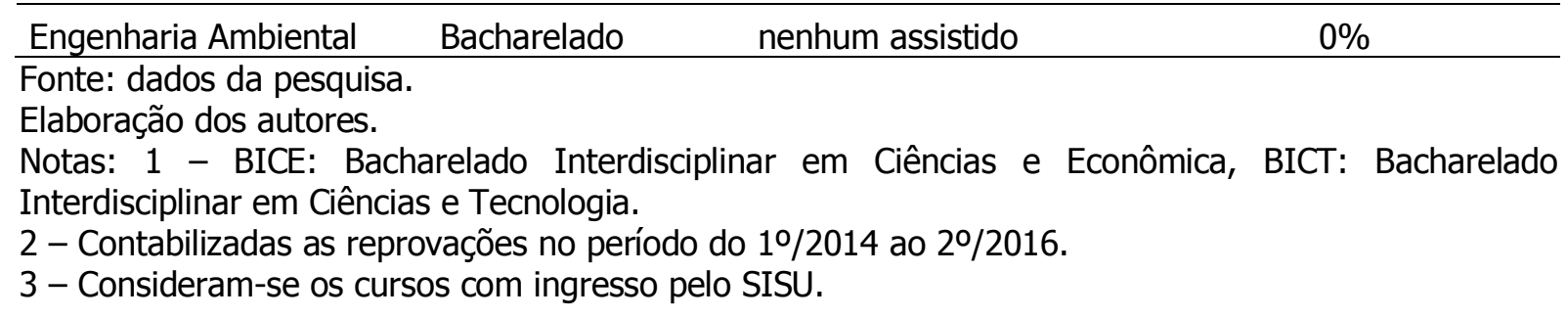

A pesquisa de Macedo (2012) sobre a evasão do curso de Física Licenciatura na Universidade Federal Fluminense pode contribuir para o estudo das dificuldades dos alunos do curso na UNIFAL-MG. Oscar Hipólito citado por Macedo (2012) ressalta que, além das dificuldades financeiras, outro problema que afeta a evasão é a falta de acompanhamento acadêmico pedagógico principalmente para alunos oriundos de escolas públicas.

Visualizando o IRp dos 25 cursos na Figura 1, percebe-se do lado direito do gráfico uma maior quantidade de cursos com IRp $>0,00$, que significa uma maior proporção de alunos assistidos sem reprovação, do que do lado esquerdo $(-1,00<\operatorname{IRp}<0,00)$ que agrupa os cursos em que a proporção de alunos assistidos com pelo menos uma reprovação foi maior. No centro (IR $p=0,00)$, estão os quatro cursos em que a proporção de reprovação foi igual entre não assistidos e assistidos. Esse maior número de cursos com IRp>0,00 demonstram a efetividade do PNAES na UNIFAL-MG.

Em relação aos ingressantes no segundo semestre de 2014 Tabela 5, é alta a taxa de reprovação entre os alunos não assistidos e assistidos.

Observando-se os valores do IRp (Tabela 5), BICT e Odontologia possuem índice menor do que zero. Nesse caso, a proporção de alunos assistidos com pelo menos uma reprovação é maior do que a proporção de alunos não assistidos. Já os outros quatro cursos, Química Bacharelado, BICE, Ciências Biológicas Licenciatura e Farmácia apresentam o índice de reprovação relativa igual ou maior do que zero. Esse resultado do índice de reprovação mostra que o PNAES possibilitou aos alunos assistidos ficarem no mesmo patamar e até superar os alunos não assistidos no aspecto pertinente à reprovação. 
FIGURA 1- Gráfico com os índices de reprovações relativas dos alunos ingressantes no $10 / 2014$

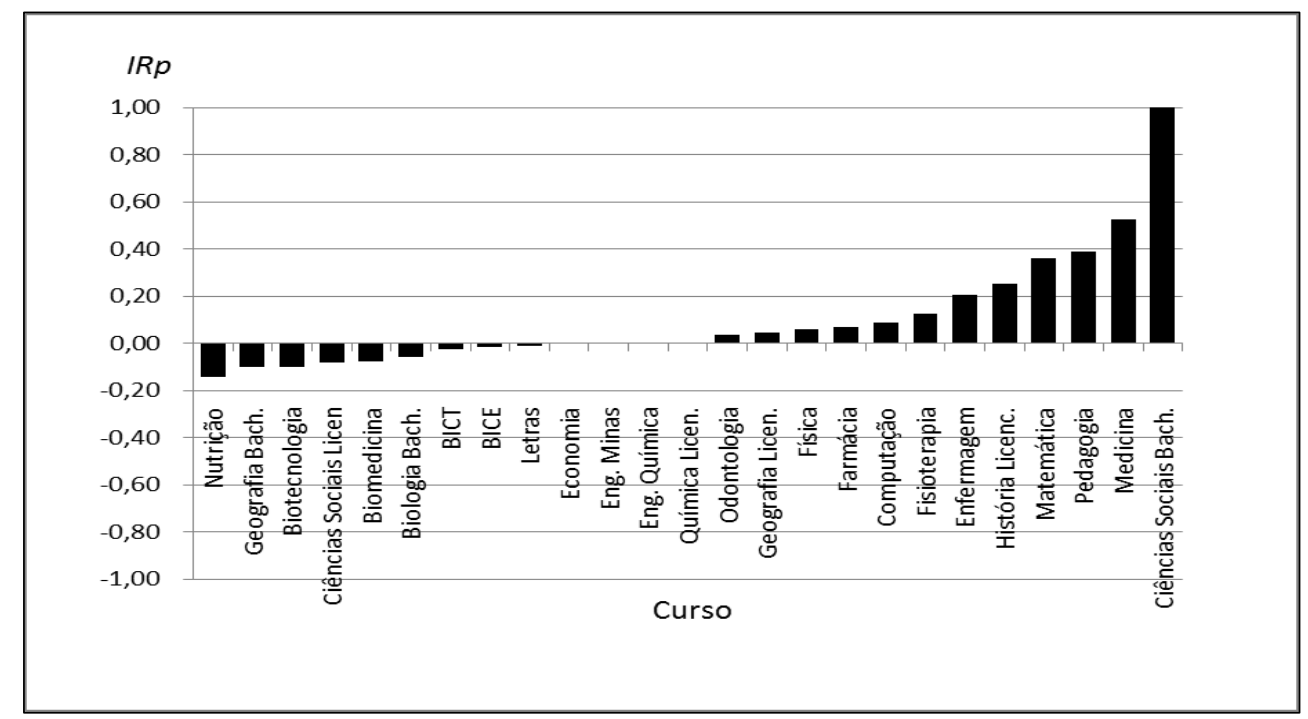

Fonte: dados da pesquisa.

Elaboração dos autores.

Notas: 1 - BICE: Bacharelado Interdisciplinar em Ciências e Econômica, BICT: Bacharelado Interdisciplinar em Ciências e Tecnologia.

2 - Contabilizadas as reprovações no período do 1\%/2014 ao 2\%/2016.

3 - Considerou-se os cursos com ingresso pelo SISU.

Observando a Tabela 5, o curso BICE com $\operatorname{IRp}=0,02$ teve a proporção de alunos assistidos com pelo menos uma reprovação menor do que a proporção de alunos não assistidos com reprovação.

TABELA 5 - Índice de reprovação relativa e taxa de reprovação relativa dos alunos ingressantes no $2 \% / 2014$

\begin{tabular}{llcc}
\hline \multicolumn{1}{c}{ Curso } & Modalidade & $\begin{array}{c}\text { IRp- Índice de reprovação } \\
\text { relativa }\end{array}$ & $\begin{array}{c}\text { TRp-Taxa de } \\
\text { reprovação }\end{array}$ \\
\hline BICT & Bacharelado & $-0,03$ & $94 \%$ \\
\hline Odontologia & Bacharelado & $-0,02$ & $82 \%$ \\
\hline Química & Bacharelado & 0,00 & $100 \%$ \\
\hline BICE & Bacharelado & 0,02 & $97 \%$ \\
\hline Ciências Biológicas & Licenciatura & 0,11 & $86 \%$ \\
\hline Farmácia & Bacharelado & 0,28 & $73 \%$ \\
\hline Engenharia de Minas & Bacharelado & nenhum aluno assistido & $100 \%$ \\
\hline
\end{tabular}

Fonte: dados da pesquisa.

Elaboração dos autores.

Notas: 1 - BICE: Bacharelado Interdisciplinar em Ciências e Econômica, BICT: Bacharelado Interdisciplinar em Ciências e Tecnologia.

2 - Contabilizadas as reprovações no período do 2\%/2014 ao 2\%/2016.

3 - Considerou-se os cursos com ingresso pelo Sisu. 
Andrade (2014) e Ciribelli (2015) concordam que as reprovações ao longo do curso implicam na ultrapassagem do tempo previsto para a sua integralização e, consequentemente, na evasão. Conforme o Regulamento Geral dos Cursos de Graduação da UNIFAL-MG (2016), a não integralização no tempo máximo estabelecido no Projeto Pedagógico é um dos motivos de desligamento do discente. Portanto, o rendimento acadêmico é uma questão relevante para permanência dos discentes no ensino superior. Essa hipótese pode ser verificada analisando-se conjuntamente a Tev e a TRp (Tabela 6), que mostra a relação entre reprovação em pelo menos uma disciplina e evasão na UNIFAL-MG.

TABELA 6 - Taxa de evasão e taxa de reprovação dos alunos ingressantes no $10 / 2014$ e no $20 / 2014$

\begin{tabular}{cllcc}
\hline Semestre & \multicolumn{1}{c}{ Curso } & Modalidade & $\begin{array}{c}\text { Taxa de Evasão } \\
(\text { Tev })\end{array}$ & $\begin{array}{c}\text { Taxa de Reprovação } \\
(\text { TRp })\end{array}$ \\
\hline \multirow{2}{*}{$1 \% / 2014$} & Matemática & Licenciatura & $68 \%$ & $83 \%$ \\
\cline { 2 - 5 } & Química & Licenciatura & $62 \%$ & $100 \%$ \\
\cline { 2 - 5 } & Geografia & Bacharelado & $56 \%$ & $88 \%$ \\
\hline \multirow{2}{*}{$2 \% / 2014$} & Ciências Biológicas & Licenciatura & $52 \%$ & $86 \%$ \\
\cline { 2 - 5 } & Química & Bacharelado & $39 \%$ & $100 \%$ \\
\cline { 2 - 5 } & BICE & Bacharelado & $37 \%$ & $97 \%$ \\
\hline
\end{tabular}

Fonte: dados da pesquisa.

Elaboração dos autores.

Notas: 1 - BICE: Bacharelado Interdisciplinar em Ciências e Econômica, BICT: Bacharelado Interdisciplinar em Ciências e Tecnologia.

2 - Contabilizadas as reprovações no período do 1\%/2014 ao 2\%/2016.

3 - Considerou-se os cursos com ingresso pelo Sisu.

De acordo com os dados da Tabela 6, o curso de Química é o segundo com maior taxa de evasão no primeiro semestre de 2014, na modalidade Licenciatura, e no segundo semestre de 2014, na modalidade Bacharelado. Em ambos os semestres, a taxa de reprovação é $100 \%$, corroborando a hipótese da relação entre reprovação e evasão na UNIFAL-MG. Sobre o curso de Química, os estudos nas décadas de 1980 e início de 1990 de Braga et al. (1997), Manrique (1999), Santos (1996) e Silva et al. (1995) citados por Cunha, Tunes e Silva (2001) já apontavam que a evasão do curso de Química era devido às reprovações.

Por fim, após o cálculo dos índices de evasão relativas, foi constatado que o PNAES foi efetivo no aspecto da evasão no primeiro e no segundo semestres de 2014, isso significa que a proporção de alunos assistidos que evadiram é igual ou menor que a proporção de alunos não assistidos evadidos. Por conseguinte, o PNAES foi efetivo com relação à evasão e atingiu o objetivo de minimizar os efeitos resultantes das desigualdades sociais e regionais na permanência de alunos em cursos de graduação presencial na UNIFAL-MG.

Quanto ao objetivo, comparando-se o rendimento acadêmico entre alunos assistidos e não assistidos, o PNAES foi efetivo em 16 dos 25 cursos no primeiro semestre de 2014. O objetivo não foi atingido em nove cursos, a saber: Nutrição, Geografia Bacharelado, Biotecnologia, Ciências Sociais Licenciatura, Biomedicina, Ciências Biológicas 
Bacharelado, Bacharelado Interdisciplinar em Ciência e Economia, Bacharelado Interdisciplinar em Ciência e Tecnologia e Letras Licenciatura. No segundo semestre de 2014, com relação à reprovação, o PNAES foi efetivo em quatro cursos e não atingiu o objetivo no curso de Odontologia e Bacharelado Interdisciplinar em Ciência e Tecnologia.

O PNAES foi efetivo com relação à evasão para todos os cursos no primeiro e segundo semestre de 2014. Quanto à reprovação, observou-se que o PNAES, em alguns cursos, não atingiu o objetivo de igualar o rendimento acadêmico entre alunos não assistidos e assistidos, com isso o processo de avaliação gerou informações que apontam a importância de estudos para levantamento das dificuldades que causam reprovações dos alunos assistidos.

\section{CONSIDERAÇÕES FINAIS}

Após o cálculo do índice de evasão relativa (Iev) dos alunos ingressantes no primeiro e segundo semestres de 2014, concluiu-se que: os alunos assistidos evadiram em proporção igual ou menor que os alunos não assistidos, dos 25 cursos do 10/2014 e dos seis cursos do 2\%/2014 estudados. Portanto, o PNAES foi efetivo com relação ao objetivo de igualar os alunos não assistidos e assistidos com relação à evasão.

Com a mensuração do índice de reprovação relativa (IRp) para os alunos ingressantes em 2014, constatou-se que o PNAES foi efetivo em 16 dos 25 cursos analisados no primeiro semestre de 2014, como também foi efetivo em quatro dos seis cursos estudados no segundo semestre de 2014. Nos cursos nos quais o PNAES foi efetivo é possível concluir que a proporção de alunos assistidos com reprovação é igual ou menor que a proporção de alunos não assistidos, dessa maneira colocando os alunos assistidos em um patamar de rendimento acadêmico igual ou superior aos alunos não assistidos.

Considerando-se a finalidade do PNAES de ampliar as condições de permanência dos alunos no ensino superior público federal, o programa na UNIFAL-MG foi um sucesso para os discentes ingressantes no ano de 2014, uma vez que os alunos assistidos evadiram menos e na maioria dos cursos tiveram um rendimento acadêmico melhor. Entretanto, durante o processo de avaliação do PNAES, identificou-se nove cursos no $1 \% / 2014$ e dois cursos no 2\%/2014 que precisam de estudos para o levantamento das causas de reprovações dos alunos assistidos.

Sugerem-se estudos futuros para verificar se houve alunos carentes que solicitaram os auxílios da assistência estudantil e não foram contemplados devido à falta de orçamento disponível na UNIFAL-MG. Nessa situação, os alunos embora classificados como "não assistidos", podem ter evadido por motivos financeiros, implicando no descompasso entre a política acesso preconizada na Lei $n^{0} 12.711$, de 29 de agosto de 2012, Lei de Cotas, e a política de permanência do Programa Nacional de Assistência Estudantil.

Em trabalhos futuros, os índices Iev e IRp poderiam ser aplicados novamente na UNIFAL-MG para outras turmas, como também podem ser aplicados em outras Instituições de Ensino Superior (IES), lembrando que os índices são aplicados em uma população de alunos em determinado período e os resultados e interpretações são somente para população para qual os índices foram calculados. Sem alteração da fórmula, 
os índices elaborados nesta pesquisa podem se adaptarem aos critérios de outras IFES na avaliação do PNAES.

Os índices foram elaborados no contexto do PNAES de ampliar a permanência no ensino superior público federal, mas esses também podem ser aplicados para a avaliação de programas públicos em instituições de ensino superior privadas. Por exemplo, calcular o índice de evasão relativa e índice de reprovação relativa comparando os alunos que têm seus cursos financiados pelo Fundo de Financiamento Estudantil (FIES) e alunos que não recebem o FIES, ou mensurar os índices comparando alunos com bolsas do Programa Universidade para Todos (PROUNI) e os alunos que não recebem bolsas do PROUNI.

\section{REFERÊNCIAS}

ANDRADE, Jeilson B. A evasão nos Bacharelados Interdisciplinares da UFBA: um estudo de caso. 2014. 179f. Dissertação (Mestrado em Estudos Interdisciplinares sobre a Universidade) - Instituto de Humanidades, Artes e Ciências Professor Milton Santos, Universidade Federal da Bahia, Salvador, 2014.

BAUER, A., SOUZA, S. Z. Indicadores para avaliação de programas educacionais: desafios metodológicos. Ensaio: aval. pol. públ. Educ., Rio de Janeiro, v. 23, n. 86, p. 259-284, jan./mar. 2015.

BRASIL. Ministério da Educação. Portaria no 39, de 12 de dezembro de 2007. Institui o Programa Nacional de Assistência Estudantil - PNAES. Disponível em:

http://portal.mec.gov.br/arquivos/pdf/portaria_pnaes.pdf. Acesso em: 27 maio 2018.

Presidência da República. Decreto no 7.234, de 19 de julho de 2010. Dispõe sobre o Programa Nacional de Assistência Estudantil - PNAES. Disponível em:

http://www.planalto.gov.br/ccivil_03/_Ato2007-2010/2010/Decreto/D7234.htm. Acesso em: 27 maio 2018.

CASTRO, Rodrigo Batista de. Eficácia, Eficiência e Efetividade na Administração Pública. In: ENCONTRO DA ANPAD, 30, 2006, Salvador. Anais. Rio de Janeiro/RJ: ANPAD, 2006. Disponível em: http://www.anpad.org.br/enanpad/2006/dwn/enanpad2006-apsa-1840.pdf. Acesso em: 27 maio 2018.

CIRIBELLI, Bruno César De Nazareth. Retenção e Evasão Escolares no Bacharelado Interdisciplinar em Ciências Exatas da Universidade Federal de Juiz de Fora. 2015. $123 \mathrm{f}$. Dissertação (Mestrado Profissional em Gestão e Avaliação da Educação Pública) - Faculdade de Educação, Universidade Federal de Juiz de Fora, Juiz de Fora, 2015.

CUNHA, Aparecida; TUNES, Elizabeth; SILVA, Roberto Ribeiro da. Evasão do curso de Química da Universidade de Brasília: a interpretação do aluno evadido. Química Nova, São Paulo, v. 24, no 1, p. 262-280, 2001.

GERBA, Raphael Thiago. Análise da evasão de alunos nos cursos de licenciatura: estudo de caso no Instituto Federal de Educação, Ciência e Tecnologia de Santa Catarina. 2014. 149f. Dissertação (Mestrado em Administração Universitária) - Centro Socioeconômico, Universidade Federal de Santa Catariana, Florianópolis, 2014. 
MACEDO, Claudia. Evasão estudantil nos cursos de matemática, química e física da Universidade Federal Fluminense: uma silenciosa problemática. 2012. 106f. Dissertação (Mestrado em Serviço Social) - Departamento de Serviço Social, Pontifícia Universidade Católica do Rio de Janeiro. Rio de Janeiro, 2012.

MANRIQUE, W. B.; Silva, R. R. e Tunes, E. Evasão do curso de Química na Universidade Federal de Goiás. Revista da III Jornada de Produção Científica das Universidades Católicas do Centro-Oeste; Goiânia, n.139, 1999.

SANTOS, K. M. P. L. Avaliação emancipatória do curso de licenciatura plena em Química da Universidade Federal de Mato Grosso. 1996. 296f. Dissertação (Mestrado em Educação Pública), Universidade Federal de Mato Grosso, Cuiabá, 1996.

SILVA, Francisca Islandia C. da; RODRIGUES, Janete de Páscoa; BRITO, Ahecio Kleber Araújo; FRANÇA, Nanci Maria de. Evasão escolar no curso de Educação Física da Universidade Federal do Piauí. Avaliação da Educação Superior, Campinas e Sorocaba, v. 17, n. 2, p. 391-404, jul. 2012.

SILVA, R. R.; Tunes, E.; PACHÁ, L. C. L. e JUNQUEIRA, R. M.; Quim. Nova, São Paulo, v. 18, n. 210, 1995.

SOARES, Natália Caixeta. As Políticas de Assistência Estudantil na Universidade Federal de Alfenas: uma avaliação das ações no campus de Varginha entre 2009 e 2015. 2016. $99 f$. Dissertação (Mestrado Profissional em Administração Pública), Universidade Federal de Alfenas, Varginha, 2016.

UNIVERSIDADE FEDERAL DE ALFENAS. Resolução no 19/2014, de 06 de fevereiro de 2014. Regulamenta os Programas de Assistência Estudantil oferecidos pela Universidade Federal de Alfenas (UNIFAL-MG), por meio da Pró-Reitoria de Assuntos Comunitários e Estudantis (Prace). 2014. Disponível em: http://www.unifalmg.edu.br/prace/sites/default/files/anexos/resolucao_019-2014_consuni_0.pdf. Acesso em: 27 maio 2018.

Resolução no 15, de 15 de junho de 2016. Estabelece o Regulamento Geral dos Cursos de Graduação da Universidade Federal de Alfenas e dá outras providências. 2016. Disponível em: http://www.unifal-mg.edu.br/secretariageral/files/file/CEPE/2016/resolucao_152016.pdf. Acesso em: 27 maio 2018. 